\title{
Australian community health practitioners' knowledge and experience with managing urinary incontinence that begins in childhood
}

Patrina HY Caldwell, Ramesh Manocha, Sana Hamilton, Karen M Scott, Elizabeth $\mathrm{H}$ Barnes

\section{Background and objectives}

General practitioners (GPs) often see children with enuresis and daytime urinary incontinence, and adults with persistent enuresis. The aim of this study was to assess Australian community health practitioners' knowledge and experiences with managing these conditions.

\section{Methods}

Health practitioners were surveyed about their knowledge and experience managing urinary incontinence that begins in childhood. Associations between participant characteristics and knowledge/experience were examined using chi-square tests.

\section{Results}

The 1495 participants were mostly female, experienced, GPs who worked in a metropolitan area and/or saw patients with incontinence infrequently, but felt knowledgeable and confident about management of incontinence. Correct survey answers were given by $93 \%$ of participants for managing enuresis, $81 \%$ for daytime urinary incontinence (with $18 \%$ choosing inappropriate and potentially dangerous responses), and $61 \%$ for managing enuresis that has persisted into adulthood.

\section{Discussion}

Better education is needed for GPs regarding management of urinary incontinence that begins in childhood, particularly for daytime incontinence in children and enuresis that persists into adulthood.
URINARY INCONTINENCE (enuresis and daytime urinary incontinence) is encountered in approximately $10 \%$ of school-aged children. ${ }^{1}$ This stigmatising condition can affect self-esteem, health and quality of life, all of which improve with successful treatment. ${ }^{2}$ Although there is spontaneous remission in many patients, ${ }^{3}$ urinary incontinence in childhood can progress to adulthood ${ }^{4}$ with devastating consequences. ${ }^{5}$

Although it is assumed that children with urinary incontinence would initially present to a general practitioner (GP), it is uncertain how commonly they present. One Australian study from 1996 found that only $34 \%$ of families with children who have urinary incontinence seek professional help. ${ }^{6}$ Another Australian study from 2018 found that $4-5 \%$ of paediatricians' consultations are related to enuresis. ${ }^{7}$

Despite its common presentation and the availability of clinical practice guidelines to inform management, ${ }^{8,9}$ there appears to be unwarranted variation in treatment. A study of New Zealand GPs reported that many do not feel confident about managing urinary incontinence in children. ${ }^{10}$ Lack of formal training at both undergraduate and postgraduate levels was cited to be part of the cause.

The aim of this study was to assess Australian community health practitioners' knowledge and experience with managing urinary incontinence that begins in childhood. We hoped that this information would identify the education needs of community health practitioners to inform the development of educational resources for them.

\section{Methods}

Australian health practitioners who were registered on the Healthed database were invited to participate in an online survey. Healthed is a private Australian health education organisation with a large database of health professionals who have registered to receive regular education updates and surveys (www.healthed.com. $\mathrm{au}$ ). Registrants were sent an email with a link to an online survey in SurveyMonkey. As an incentive for completing the survey, they were offered entry in a raffle for an iPad.

The 18-question survey was designed by PC and pilot tested on five health practitioners (Appendix 1, available online only). It focused on three common conditions: childhood enuresis; childhood daytime urinary incontinence; and enuresis that has persisted into adulthood (beyond 18 years of age). The survey obtained information about participants' reported frequency of seeing these conditions in their clinical practices within the previous year; their perceived level of knowledge and confidence in managing these conditions; demographic information, including participant age, gender, years of practice, work setting (private practice/public setting) and location of practice (rural/metropolitan); and participants' perceived learning needs.

The survey also included four questions that tested participants' knowledge about managing the three conditions. There was one multiple choice question with a single best answer relating to the most common cause of enuresis in childhood (the most common of the three conditions). The remaining three questions had multiple 
answer options about first-line treatments for each of the three conditions (where there were multiple correct answer combinations).

The recommendations of the International Children's Continence Society ${ }^{11,12}$ were used to determine the correct answers. Urotherapy (ie education and advice about fluids, diet, toileting practice, and bladder and bowel habits) was accepted as a correct answer for the management of all types of urinary incontinence, and nappies or pads were also accepted as correct as long as they were not the only option chosen. There was an ideal answer for each of the three condtions:

- urotherapy and enuresis alarm training for childhood enuresis (where an enuresis alarm, triggered by the child's wetting, is used to train the child to eventually withhold urination or wake to void when their bladder is full during sleep)

- urotherapy for childhood daytime urinary incontinence

- urotherapy and desmopressin (a synthetic vasopressin that reduces the total overnight urine production) for enuresis that has persisted into adulthood.

However, other reasonable answers were also accepted as correct. For example, in the first-line management of children with enuresis, acceptable correct answers included: urotherapy, either alone or in combination with enuresis alarm therapy; nappies in combination with urotherapy and/or enuresis alarm therapy; and desmopressin, but only if alarm training was also chosen.

However, any answer that included tricyclic antidepressants as first-line management was considered incorrect. Tricyclic antidepressants are no longer recommended as first-line therapy because of the potential risk of side effects, and the availability of more effective treatments. Although urotherapy is the recommended first-line management for childhood daytime urinary incontinence, we also accepted anticholinergics as a correct answer as they are a recommended treatment for overactive bladder, which is a common cause for daytime urinary incontinence in children. As there is little guidance about the first-line management of enuresis that has persisted into adulthood, ${ }^{13-15}$ we decided that any of the following answers was correct, on the basis of available evidence: urotherapy, alarm training or desmopressin, alone or in combination.

The survey data were de-identified and entered into a database for analysis. Demographic data were described by frequencies and percentages. Associations between participant demographics and responses to knowledge questions were examined using chi-square tests.

\section{Results}

\section{Demographics}

The survey was emailed to the 17,361 health practitioners registered on the Healthed database in December 2016, with 1495 (8.6\%) completing the survey (Table 1). Most respondents were female $(84 \%)$, aged $\geq 45$ years $(70 \%)$, had $\geq 10$ years in clinical practice $(78 \%)$ and worked in a metropolitan area (69\%). Most were GPs (67\%), with 30\% nurses and $3.1 \%$ participants employed in other healthcare professions (eg pharmacists, psychologists, allied health professionals or complementary medicine practitioners).

\section{Frequency of seeing incontinence in their practices}

Most participants reported seeing patients with urinary incontinence infrequently. In the frequency category of 'seen $\geq 1$ patient per month', $10 \%$ of participants reported seeing children with enuresis, $6 \%$ saw children with daytime urinary incontinence, and $1.1 \%$ saw enuresis that persisted into adulthood. In the previous year, $84 \%$ of participants had not seen any patients with enuresis that persisted into adulthood.

\section{Perceived knowledge and confidence with managing urinary incontinence}

Most participants perceived that they were knowledgeable about managing childhood urinary incontinence (Table 2): $88 \%$ reported being slightly or very knowledgeable about managing childhood enuresis and $75 \%$ reported being slightly or very knowledgeable about managing childhood daytime urinary incontinence. Participants reported being least knowledgeable about managing enuresis that has persisted into adulthood: $63 \%$ reported that they were not knowledgeable about managing this condition.

Participants' confidence in managing these conditions was similar but slightly less than their reported knowledge: $77 \%$ reported being somewhat or very confident about managing childhood enuresis, $62 \%$ about managing childhood daytime urinary incontinence and 31\% about managing adult enuresis.

Knowledge about cause of bedwetting Although childhood enuresis was the most common of the three incontinence

\section{Table 1. Participant demographics (n = 1495*)}

\begin{tabular}{lc}
\hline Gender & $1251(84)$ \\
\hline Female & $238(16)$ \\
\hline Male & \\
\hline Age (years) & $130(9)$ \\
\hline$<35$ & $315(21)$ \\
\hline $35-44$ & $410(28)$ \\
\hline $45-54$ & $634(43)$ \\
\hline$\geq 55+$ & $118(8)$ \\
\hline Years of practice & $207(14)$ \\
\hline $0-4$ & $1158(78)$ \\
\hline $5-9$ &
\end{tabular}

Profession

\begin{tabular}{lr} 
General practitioner & 996 (67) \\
\hline Nurse/midwife & $446(30)$ \\
\hline Other & $47(3)$
\end{tabular}

Practice location

Metropolitan

$1023(69)$

Rural/remote

$465(31)$

*Missing responses for each question have been excluded from the denominator 
conditions seen by participants, less than half $(48 \%)$ correctly identified the most common cause of enuresis in children as abnormal physiology of sleep and bladder function. Thirty-four per cent of participants thought the most common cause was a delay in developing toileting skills, $10 \%$ attributed it to psychological causes, $2 \%$ thought it was most commonly caused by a child's unwillingness to get out of bed to void, and 6\% reported not knowing the answer.

\section{Participant choice of first-line management for incontinence}

For the questions with multiple answer options about first-line management of the three conditions, most participants gave a correct answer (Table 3 ): 93\% selected a correct response for childhood enuresis, $81 \%$ for childhood daytime urinary incontinence, and $61 \%$ for enuresis that has persisted into adulthood. For treatments for childhood enuresis, $49 \%$ chose enuresis alarm therapy (the recommended first-line management), $8 \%$ chose desmopressin (an alternative first-line management in certain situations where alarm training is contraindicated) and $2 \%$ chose tricyclic antidepressants (a treatment that had previously been used for managing enuresis, but is no longer recommended as first-line therapy).

The first-line treatment for daytime urinary incontinence was less well understood. Eight per cent of participants chose desmopressin, 7\% chose enuresis alarm therapy and $2 \%$ chose tricyclic antidepressants, all of which are treatments for bedwetting and inappropriate for treating daytime urinary incontinence. First-line treatment for enuresis that has persisted into adulthood was even less well understood. Participants more commonly chose medication (such as desmopressin, tricyclic antidepressants and anticholinergics) as a first-line therapy for managing adult enuresis (Table 3): $27 \%$ chose anticholinergics as first-line therapy, although anticholinergics are used for treating overactive bladder and daytime urinary incontinence; $17 \%$ chose desmopressin and $13 \%$ chose alarm training.

\section{Association between respondent characteristics and correct answers}

For first-line management of childhood urinary incontinence (enuresis and daytime incontinence), participants who were female, aged $<55$ years, and worked as a GP were more likely to choose a correct response, but there was no association with practice location, years of practice and frequency of seeing patients with these conditions (Table 4). Those who reported being knowledgeable about managing each condition were more likely to choose a correct response for that condition.

However, for first-line management of enuresis that has persisted into adulthood, participants who were female, worked as a GP and were practising in a metropolitan location were more likely to choose a correct response, whereas age and years

Table 2. Participants' perceived knowledge and confidence in managing urinary incontinence

\begin{tabular}{|c|c|c|c|c|c|c|}
\hline & \multicolumn{3}{|c|}{ Perceived knowledge } & \multicolumn{3}{|c|}{ Confidence } \\
\hline Children with bedwetting & $182(12)$ & $1092(74)$ & $194(13)$ & $334(23)$ & $958(65)$ & $192(13)$ \\
\hline $\begin{array}{l}\text { Children with } \\
\text { daytime wetting }\end{array}$ & $360(25)$ & $1029(70)$ & $76(5)$ & 559 (38) & $852(56)$ & $68(5)$ \\
\hline $\begin{array}{l}\text { Adults with bedwetting } \\
\text { that began in childhood }\end{array}$ & $921(63)$ & $511(35)$ & $32(2)$ & $1021(69)$ & $432(29)$ & $26(2)$ \\
\hline
\end{tabular}

Table 3. Participants' reported first-line management for incontinence conditions*

\begin{tabular}{lcccccc}
\hline & Urotherapy \% & $\begin{array}{c}\text { Enuresis } \\
\text { alarm \% }\end{array}$ & Anticholinergics \% & Desmopressin \% & $\begin{array}{c}\text { Tricyclics \% } \\
\text { or pads \% }\end{array}$ & $\begin{array}{c}\text { Correct } \\
\text { answer \% }\end{array}$ \\
\hline Children with bedwetting & 95 & 49 & 3 & 8 & 2 & 26 \\
\hline $\begin{array}{l}\text { Children with daytime } \\
\text { wetting }\end{array}$ & 95 & 7 & 7 & 8 & 28 & 28 \\
\hline $\begin{array}{l}\text { Adults with bedwetting } \\
\text { that began in childhood }\end{array}$ & 82 & 13 & 27 & 17 & 13 & 26 \\
\hline
\end{tabular}

*Participants could choose more than one response, so percentages do not sum to 100 
Table 4. Association between participant characteristics and correct answers about first-line management

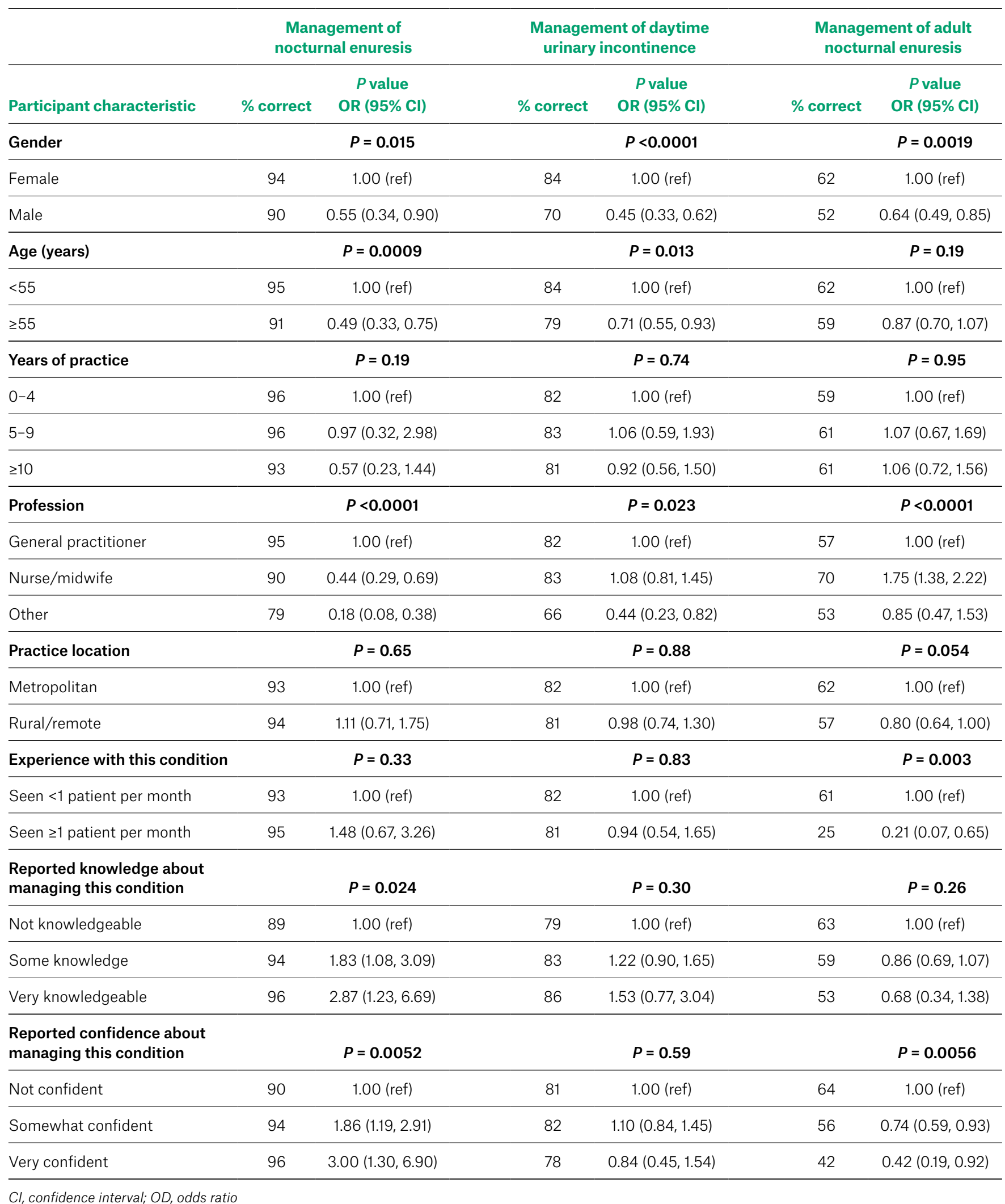

Cl, confidence interval; $O D$, odds ratio 
of practice made no difference. Those who reported a higher frequently of seeing patients with enuresis that has persisted into adulthood, and those who reported being more knowledgeable and confident with managing this condition, were sometimes less likely to choose a correct response.

\section{Discussion}

Most survey respondents had seen children with enuresis, and at least half had seen children with daytime urinary incontinence in the previous year. However, very few had seen patients with enuresis that had persisted into adulthood. This could be because adult enuresis is less common than childhood enuresis (occurring in about $2 \%$ of adults), ${ }^{16}$ or because adults with enuresis may not be aware that treatments are available..$^{5}$ It could also be because of the stigmatising nature of the condition, with adults being too embarrassed to seek professional help for their problem. One study found that $20 \%$ of adults with persistent enuresis have never consulted a doctor about their problem. ${ }^{17}$

The majority of participants were female, aged $\geq 45$ years, had $\geq 10$ years in clinical practice, worked in a metropolitan area and were GPs. This is consistent with the demographics of health practitioners registered on the Healthed database, which has a focus on women and children's health. The association between female gender, employment as a GP and choice of correct answers for the knowledge questions may reflect the interest that female health practitioners have in conditions such as urinary incontinence that begins in childhood. It may also reflect the parents' preference for seeking help for their child from female GPs, who are perceived to be more empathetic. ${ }^{18}$

Although almost all practitioners chose a correct first-line management response for childhood urinary incontinence, they were generally less knowledgeable about managing enuresis that has persisted into adulthood. The selection of some incorrect answers about first-line management, particularly for managing childhood daytime urinary incontinence, is concerning: some of the chosen options are potentially harmful, such as the use of desmopressin for treating daytime urinary incontinence, which could cause hyponatraemia and seizures if given during the day without fluid restriction. Other options, such as enuresis alarms, are inappropriate in treating daytime urinary incontinence.

This study highlights the education needs of community health practitioners in regard to the management of urinary incontinence that begins in childhood. If not adequately addressed in childhood, urinary incontinence can progress to adulthood, increasing the risk of depression, low self-esteem and sleep disturbances, ${ }^{16}$ and affecting lifestyle choices and quality of life. ${ }^{5}$

\section{Limitations}

The response rate of this study is very low, despite the large number of participants. Our findings are likely to reflect the response of community health professionals who are more interested in urinary incontinence that begins in childhood, and may not necessarily be representative of all community health professionals. Therefore, the experience and knowledge of Australian community health professionals in managing childhood enuresis, childhood daytime urinary incontinence and enuresis that has persisted into adulthood in general may be lower than reported in this study.

\section{Conclusions}

There is variability in Australian community health practitioners' knowledge about managing urinary incontinence that begins in childhood. There is a need to improve the education of Australian GPs and raise public awareness about this common but often neglected condition. There is also a need for more research to address the needs of adults with persistent enuresis.

\section{Authors}

Patrina HY Caldwell BMed, FRACP, PhD, Senior Staff Specialist Paediatrician, The Children's Hospital at Westmead, Sydney Children's Hospitals Network; Discipline of Child and Adolescent Health, University of Sydney, NSW. patrina.caldwell@health.nsw.gov.au
Ramesh Manocha MBBS, BSc (med), PhD, general practitioner, Healthed Pty Ltd, NSW.

Sana Hamilton BAppSc (nursing), MPH, Research Assistant, The Children's Hospital at Westmead, Sydney Children's Hospitals Network, NSW

Karen M Scott BEd, MA, PhD, Senior Lecturer, Discipline of Child and Adolescent Health, University of Sydney, NSW

Elizabeth H Barnes BAppSc, MStat, Research Fellow, NHMRC Clinical Trials Centre, The University of Sydney, NSW

Competing interests: RM reports that outside the submitted work, Ferring Pharmaceuticals occasionally participate in exhibitions at Healthed events, for which RM is CEO.

Funding: None.

Provenance and peer review: Not commissioned, externally peer reviewed.

\section{Acknowledgement}

The authors wish to acknowledge the support of Healthed in this project (www.healthed.com.au).

\section{Declaration}

This paper contains a more detailed exploration of our work, which was published as an abstract in the Journal of Paediatrics and Child Health in the Special Issue: Abstracts for the RACP Congress 2017.19 A copyright exemption has been granted by the Journal of Paediatrics and Child Health for the authors to use parts of the published abstract in this article. (License Number 4415091217556; License date Aug 23 2018). Preliminary data from this project were presented as a poster presentation at the RACP Congress (2017), the 26th National Conference on Incontinence (2017) and as a poster presentation at the International Children's Continence Society Conference in Rome (2018).

\section{References}

1. von Gontard A, Heron J, Joinson C. Family history of nocturnal enuresis and urinary incontinence: Results from a large epidemiological study. J Urol 2011;185(6):2303-06. doi: 10.1016/j. juro.2011.02.040.

2. Hägglöf $B$, Andrén $O$, Bergström $E$, Marklund L, Wendelius M. Self-esteem in children with nocturnal enuresis and urinary incontinence: Improvement of self-esteem after treatment. Eur Urol 1998;33 Suppl 3:16-19.

3. Forsythe WI, Redmond A. Enuresis and spontaneous cure rate. Study of 1129 enuretis. Arch Dis Child 1974;49(4):259-63.

4. Kuh D, Cardozo L, Hardy R. Urinary incontinence in middle aged women: Childhood enuresis and other lifetime risk factors in a British prospective cohort. J Epidemiol Community Health 1999;53(8):453-58.

5. Wilson GJ. The lived experience of bedwetting in young men living in Western Australia. Aust NZ Continence J 2014;20(4):188.

6. Bower WF, Moore KH, Shepherd RB, Adams RD. The epidemiology of childhood enuresis in Australia. Br J Urol 1996;78(4):602-06.

7. De S, Teixeira-Pinto A, Sewell JR, Caldwell PH. Prevalence, patient and consultation characteristics of enuresis in Australian paediatric practice. J Paediatr Child Health 2018;54(6):620-24. doi: 10.1111/jpc.13834.

8. Nunes VD, O'Flynn N, Evans J, Sawyer L, Guideline Development Group. Management of bedwetting in children and young people: Summary of NICE guidance. BMJ 2010;341:c5399. doi: 10.1136/bmj. c5399. 
9. Deshpande AV, Craig JC, Smith GHH, Caldwell PHY. Management of daytime urinary incontinence and lower urinary tract symptoms in children. J Paediatr Child Health 2012;48(2):E44-52.

10. Dovey S, McNaughton T, Tilyard M, Gurr E, Jolleys J, Wilson D. General practitioners' opinions of continence care training. N Z Med J 1996;109(1029):340-43.

11. Neveus T, Eggert P, Evans J, et al. Evaluation of and treatment for monosymptomatic enuresis: A standardization document from the International Children's Continence Society. J Uro 2010;183(2):441-47. doi: 10.1016/j.juro.2009.10.043.

12. Hoebeke P, Bower W, Combs A, De Jong T, Yang S. Diagnostic evaluation of children with daytime incontinence. J Urol 2010;183(2):699-703. doi: 10.1016/j.juro.2009.10.038.

13. Hirasing RA, van Leerdam FJ, Bolk-Bennink L, Janknegt RA. Enuresis nocturna in adults. Scand J Urol Nephrol 1997;31(6):533-36.

14. Janknegt RA, Zweers HM, Delaere KP, Kloet AG, Khoe SG, Arendsen HJ. Oral desmopressin as a new treatment modality for primary nocturnal enuresis in adolescents and adults: A double-blind, randomized, multicenter study. Dutch Enuresis Study Group. J Urol 1997;157(2):513-17.

15. Vandersteen DR, Husmann DA. Treatment of primary nocturnal enuresis persisting into adulthood. J Urol 1999;161(1):90-92.

16. Yeung CK, Sihoe JD, Sit FK, Bower W, Sreedhar B, Lau J. Characteristics of primary nocturnal enuresis in adults: An epidemiological study. BJU Int 2004;93(3):341-45.

17. Nappo S, Del Gado R, Chiozza ML, Biraghi M, Ferrara P, Caione P. Nocturnal enuresis in the adolescent: A neglected problem. BJU Int 2002;90(9):912-17.

18. Howick J, Steinkopf L, Ulyte A, Roberts N, Meissner K. How empathic is your healthcare practitioner? A systematic review and metaanalysis of patient surveys. BMC Med Educ 2017;17(1):136. doi: 10.1186/s12909-017-0967-3.

19. Caldwell PHY, Manocha R, Hamilton S, Scott K, Barnes $\mathrm{EH}$. Experience and knowledge in managing childhood urinary incontinence among Australian community health practitioners. J Paediatr Child Health 2017;53(S3):19-20. doi: 10.1111/.jpc.13597_1. 